\title{
High Detection Rates of Urine Mycobacterium tuberculosis in Patients with Suspected Miliary Tuberculosis
}

\author{
Toshinobu Yokoyama ${ }^{1,2}$, Takashi Kinoshita ${ }^{1}$, Masaki Okamoto ${ }^{1}$, Kazuko Matsunaga ${ }^{3}$, \\ Tomoko Kamimura ${ }^{4}$, Masaharu Kinoshita ${ }^{5}$, Toru Rikimaru ${ }^{3}$, Kazuhito Taguchi ${ }^{6}$, \\ Tomoaki Hoshino ${ }^{1}$ and Tomotaka Kawayama ${ }^{1}$
}

\begin{abstract}
Objective The utility of detecting Mycobacterium tuberculosis in urine samples from patients with pulmonary tuberculous with diffuse small nodular shadows (suspected miliary tuberculosis (MTB)) is still unclear in Japan. A retrospective cross-sectional study was conducted to investigate the detection rates of M. tuberculosis in urine of patients with suspected MTB.

Methods Among 687 hospitalized patients with tuberculosis, 45 with culture-confirmed suspected MTB and the data of culture and polymerase chain reaction (PCR) for M. tuberculosis in urine and sputum samples were investigated. The detection rates of M. tuberculosis in urine using cultures and PCR were calculated. The detection rate of urine was then compared with that of bone marrow aspiration.

Results Fourteen patients with suspected MTB were ultimately analyzed. A diagnosis of miliary tuberculosis was suspected in all patients before anti-tuberculosis chemotherapy. Positive results by PCR (11 [78.6\%] cases) and culture (8 [57.1\%]) were obtained from urine samples. In patients with suspected MTB, there was no significant difference in the detection rates between M. tuberculosis in urine using a combination of PCR and culture $(85.6 \%$ [12/14 cases]) and bone marrow aspiration (66.7\% [8/12 cases]) $(\mathrm{p}>0.05)$.

Conclusion Using PCR and culture, we demonstrated high detection rates of M. tuberculosis in the urine of patients with suspected MTB. A combination of PCR and culture compared favorably with the detection rates achieved with bone marrow aspiration. We believe that detection of $M$. tuberculosis from urine and sputum samples may be easy and safe for patients with disseminated tuberculosis infections such as definitive MTB.
\end{abstract}

Key words: tuberculosis, pulmonary diffuse small nodular shadows, urine, polymerase chain reaction

(Intern Med 56: 895-902, 2017)

(DOI: 10.2169/internalmedicine.56.7792)

\section{Introduction}

Tuberculosis is a leading cause of morbidity and mortality in Asian countries, including Japan (1-3). In 2014, the Ministry of Health, Labour and Welfare of Japan reported that the incidence of tuberculosis infection in the general population was 15.4 per 100,000, and that 2,099 patients had died of the disease that year (4). The report also expressed concern that the number of patients with miliary tuberculosis
(MTB) would likely increase in the population of immunosuppressed individuals with human immunodeficiency virus (HIV) infection and acquired immune deficiency syndrome (AIDS), and that as more patients receive immunosuppressive medication, the incidence and mortality of patients with tuberculosis infections would continue to increase in Japan (4-8). MTB is a potentially lethal form of tuberculosis infection resulting from disseminated massive lymphohematogenous Mycobacterium (M.) tuberculosis bacilli $(9,10)$. A diagnosis of MTB is often difficult because the signs-such

\footnotetext{
${ }^{1}$ Division of Respirology, Neurology and Rheumatology, Department of Medicine, Kurume University School of Medicine, Japan, ${ }^{2}$ Higashiaburayama Clinic, Japan, ${ }^{3}$ Respiratory Medicine, Fukuoka Sanno Hospital, Japan, ${ }^{4}$ Respiratory Medicine, Asakura Medical Association Hospital, Japan, ${ }^{5}$ Respiratory Medicine, Nagata Hospital, Japan and ${ }^{6}$ Respiratory Medicine, Kyushu Medical Center, Japan

Received for publication June 1, 2016; Accepted for publication August 24, 2016

Correspondence to Dr. Tomotaka Kawayama, kawayama_tomotaka@med.kurume-u.ac.jp
} 
as a fever, weight loss, and night sweats-are very nonspecific, and histological evidence of tuberculosis infection from multiple organs needs to be obtained by a biopsy, surgery, or autopsy $(9,10)$. A biopsy is often invasive and difficult in patients with a poor general condition. However, chest radiography or high-resolution computed tomography (HRCT) typically reveal diffuse disseminated pulmonary infiltrations with a random distribution, or multiple welldefined small nodules in the lung lobes of patients with MTB.

We therefore hypothesized that detection of M. tuberculosis from two different organs, namely the respiratory tract (sputum) and urinary tract (urine), might be helpful for a diagnosis of disseminated tuberculosis infections such as MTB. While the detection rates of $M$. tuberculosis in the urine of patients with disseminated tuberculosis infections are still unclear, previous studies have demonstrated that the detection rates in urine by polymerase chain reaction (PCR) range from $10-60 \%$ in patients with any form of tuberculosis infection (11-16). To our knowledge, no comparative studies have simultaneously examined the detection rate of M. tuberculosis in urine and sputum by smear, culture, and PCR versus the findings of bone marrow aspiration in patients with suspected MTB in Japan.

To investigate the utility of detection of M. tuberculosis bacilli and genes from sputum and urine samples by culture and PCR and to compare the detection rates between them and the findings of bone marrow aspiration, we conducted the present retrospective, cross-sectional study of tuberculosis patients with diffuse pulmonary small nodular shadows on chest HRCT (suspected MTB).

\section{Materials and Methods}

\section{Patients}

This retrospective cross-sectional study was conducted in accordance with the Good Clinical Practice (GCP) guidelines and Helsinki Declaration and opened by the University Hospital Medical Information Network (UMIN) system (UMIN No. R000024115, February 5, 2016). All data were obtained from archived medical records and images after obtaining approval from the ethics committee of Kurume University (GCP No. 15261, February 29, 2016).

The patients with suspected MTB were selected retrospectively. The inclusion criteria were 1) hospitalization because of active tuberculosis infection at Kurume University Hospital between January 1, 1997 (when genetic detection of $M$. tuberculosis from urine samples by PCR was started at our laboratory), and December 31, 2006 (when isolation rooms for patients with tuberculosis infections were completely closed in Kurume University Hospital); 2) presence of any clinical symptoms such as a fever $\left(>38^{\circ} \mathrm{C}\right)$, malaise and weakness, weight loss, night sweats, cough, sputum, and dyspnea; 3) radiographic evidence of diffuse disseminated pulmonary infiltrations with a random distribution and mul- tiple well-defined small nodules but no limited infiltration or consolidations, mass lesions or cavitations, in the lung lobes on chest HRCT (suspected MTB) before anti-tuberculosis chemotherapy; and 4) available data from examinations of sputum and urine smears, culture, and PCR for M. tuberculosis on the day before and seven days after antituberculosis chemotherapy. The definition of active tuberculosis infections was based on a culture confirmation of $M$. tuberculosis bacilli from any clinical specimens during the clinical course. Radiographic findings were assessed from archived chest HRCT images by four independent investigators (two thoracic radiologists and two specialists in tuberculosis infection) in a single-blinded manner, and the findings were accepted by consensus among three or more of the investigators.

The patient characteristics, initial symptoms, underlying diseases, anti-tuberculosis chemotherapy regimens, findings of systemic enhanced CT or magnetic resonance imaging (MRI), bone marrow specimens and test date, and outcomes were also accessed in selected cases. Underlying diseases that were risk factors for MTB, or disseminated and extrapulmonary tuberculosis were also selected in accordance with a previous review (9).

\section{Diagnosis of definitive and clinical MTB and ex- trapulmonary tuberculosis}

Definitive MTB was established on the basis of histological findings of caseating granuloma and/or detection of $M$. tuberculosis bacillus antigens in multiple (at least two) organs by a biopsy, surgery, or autopsy $(9,10)$. Clinical MTB was diagnosed based on a histological confirmation of tuberculosis infections in bone marrow specimens $(10,17)$ and/or other organs by a biopsy, surgery, or autopsy (9). The PCRand/or culture-confirmed but not pathologically confirmed patients were excluded from the category of clinical MTB. In bone marrow specimens, findings of caseating granuloma and/or M. tuberculosis were recognized as indicative of tuberculosis infection in accordance with a previous report (17). Bone marrow findings were re-checked by a pathologist after being evaluated by the screeners. Extrapulmonary tuberculosis was diagnosed on the basis of not only histological findings but also any abnormal findings of systemic medical imaging, even if there was no histological evidence of tuberculosis infection $(9,10,17)$.

\section{Examination of $M$. tuberculosis bacilli and gene in sputum and urine samples using smear, culture and PCR techniques}

Sputum samples were obtained by spontaneous expectoration or induced using a nebulizer in the morning before breakfast. Urine samples were obtained as $10-\mathrm{mL}$ spots immediately after waking in the morning. Pellets of urine sediment were obtained by centrifugation at 4,500 rpm (room temperature). Sputa and pellets of urine sediment were used directly for smear microscopy with Ziehl-Neelsen staining and for culture with Ogawa egg medium and identification 
687 patients with active tuberculosis infections were hospitalized at Kurume University Hospital

between Jan. 1st, 1997 and Dec. 315t, 2006

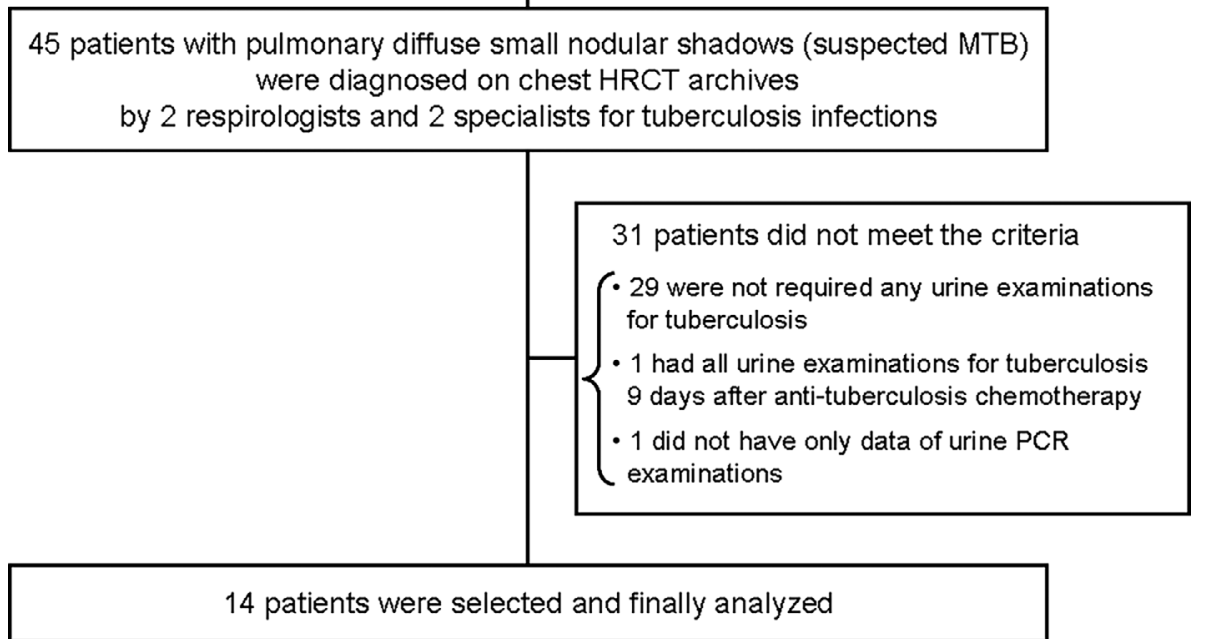

Figure. Study design. HRCT: high-resolution computed tomography, MTB: miliary tuberculosis, PCR: polymerase chain reaction

of M. tuberculosis bacilli using DNA-DNA hybridization kits (DDH Mycobacteria Kyokuto; Kyokuto Pharmaceutical Industrial Ltd., Tokyo, Japan) (18, 19).

The remaining sputum samples after treatment with $\mathrm{N}$ acetyl-L-cysteine- $\mathrm{NaOH}$ and pellets of urine sediment were used for the detection of a specific M. tuberculosis bacillus gene (584-bp region of the 16S rRNA gene) using PCR kits (Amplicor MTB; Roche Diagnostic Systems, Somerville, NJ, USA). Gene amplification was performed using a thermal cycler (PC800; Astec, Fukuoka, Japan) with the following program: holding at $50^{\circ} \mathrm{C}$ for 2 minutes; 2 cycles of $98^{\circ} \mathrm{C}$ for 20 seconds, $62^{\circ} \mathrm{C}$ for 20 seconds, and $72^{\circ} \mathrm{C}$ for 45 seconds; 35 cycles of $94^{\circ} \mathrm{C}$ for $20 \mathrm{~s}, 62^{\circ} \mathrm{C}$ for 20 seconds, and $72^{\circ} \mathrm{C}$ for 45 seconds; holding at $72^{\circ} \mathrm{C}$ for 5 minutes; and holding at $72^{\circ} \mathrm{C}$ indefinitely $(12,20,21)$.

Detection of acid-fast bacilli was recognized as a positive result on smear microscopy $(1,000 \times)$ by two independent experienced technicians $(9,10)$. Identification of $M$. tuberculosis bacilli by DNA-DNA hybridization and detection of $M$. tuberculosis genes were performed by culture and PCR, respectively $(14,20,21)$.

\section{Statistical analysis}

The detection rates of acid-fast bacilli, and M. tuberculosis bacilli and a specific gene from sputum and urine by smear, culture, and PCR were calculated after summarizing the characteristics of patients with suspected MTB. The sensitivity, specificity, positive predictive value (PPV), and negative predictive value (NPV) for detection of $M$. tuberculosis in sputum and urine by PCR were compared with those obtained by smear and culture in patients with suspected, definitive, and clinical MTB. The mean time differences (days \pm standard deviation $[\mathrm{SD}]$, range) were calcu- lated for the sampling time between PCR and/or culture, and bone marrow aspiration. Differences with $\mathrm{p}<0.05$ were considered to be statistically significant. The statistical analysis was performed using the JMP version $9.0^{\circledR}$ statistical software package (SAS Institute Japan Inc., Tokyo, Japan).

\section{Results}

Among 687 patients with tuberculosis infections hospitalized at our institution during the study period, 45 with suspected MTB were identified by the 4 independent investigators. After excluding 31 patients who did not meet the criteria of the study, the 14 patients (mean age $\pm \mathrm{SD}=63.5 \pm$ 17.0; men:women $=8: 6$ ) who met all of the inclusion criteria were ultimately selected for inclusion (Figure).

Table 1 shows that $1(7.1 \%)$ of the 14 patients with suspected MTB died due to multiple organ failure without autopsy after receiving anti-tuberculosis chemotherapy (case 1). Eight $(71.4 \%)$ patients had at least 1 underlying disease as a risk factor for MTB (case 2, 6-9, 11, 13 and 14), whereas none had HIV infections or AIDS (9). The numbers (\%) of patients who complained of only respiratory symptoms, only general symptoms, and both, were 1 (7.1\%), 11 (78.6\%), and $2(14.3 \%)$, respectively. The numbers (\%) of patients with definitive and clinical MTB and a histological diagnosis of extrapulmonary tuberculosis infection were 0 (0\%), 9 (64.3\%), and $2(14.3 \%)$, respectively. The remaining 3 patients did not have any evidence of pathological findings (case 2, 11 and 13). One (7.1\%) patient pathologically had testicle tuberculosis (case 14), and 2 (14.3\%) had suspected kidney involvements (case 9 and 12). Twelve (85.7\%) patients (case 1 and 4-14) required bone marrow aspiration, and 8 of them were positive for tuberculosis infection (case 
Table 1. Characteristics of Patients with Suspected MTB.

\begin{tabular}{|c|c|c|c|c|c|c|c|c|c|c|c|}
\hline \multirow[b]{2}{*}{ No. } & \multirow[b]{2}{*}{ Age } & \multirow[b]{2}{*}{ Gender } & \multirow[b]{2}{*}{ Underlying diseases } & \multicolumn{2}{|c|}{ Symptoms } & \multicolumn{2}{|c|}{ Diagnosis of MTB } & \multirow{2}{*}{$\begin{array}{c}\text { Involvement of } \\
\text { extrapulmonary } \\
\text { organs (examina- } \\
\text { tions) }\end{array}$} & \multirow{2}{*}{$\begin{array}{c}\text { Bone } \\
\text { marrow } \\
\text { aspiration } \\
\text { (evidence of } \\
\text { tuberculosis } \\
\text { infection) }\end{array}$} & \multirow{2}{*}{$\begin{array}{l}\text { Initial } \\
\text { anti- } \\
\text { tubercu- } \\
\text { losis } \\
\text { chemo- } \\
\text { therapy }\end{array}$} & \multirow[b]{2}{*}{ Outcome } \\
\hline & & & & $\begin{array}{l}\text { Respira- } \\
\text { tory }\end{array}$ & General & Definitive & Clinical & & & & \\
\hline 1 & 43 & M & $\begin{array}{l}\text { liver cirrhosis } \\
\text { (HCVI), alcoholism }\end{array}$ & & fever & No & Yes & & Yes (Yes) & HRS & Death \\
\hline 2 & 74 & M & renal failure & $\begin{array}{l}\text { cough, } \\
\text { sputum, } \\
\text { dyspnea }\end{array}$ & $\begin{array}{l}\text { frequent } \\
\text { urination }\end{array}$ & No & No & & NT & HREZS & Resocialization \\
\hline 3 & 25 & $\mathrm{~F}$ & & cough & fever & No & No & $\begin{array}{l}\text { meningitis (cere- } \\
\text { brospinal fluid tap) }\end{array}$ & NT & HREZ & Resocialization \\
\hline 4 & 83 & $\mathrm{~F}$ & & & fever & No & Yes & $\begin{array}{l}\text { adrenal gland (CT), } \\
\text { brain (MRI) }\end{array}$ & Yes (Yes) & HRE & Resocialization \\
\hline 5 & 76 & $\mathrm{~F}$ & & & fever & No & Yes & & Yes (Yes) & HRES & Resocialization \\
\hline 6 & 73 & M & $\begin{array}{l}\text { renal failure, need } \\
\text { for regular systemic } \\
\text { steroids }\end{array}$ & & fever, ischuria & No & Yes & & Yes (Yes) & HRE & Resocialization \\
\hline 7 & 79 & M & hemiparesis & & fever & No & Yes & & Yes (Yes) & HRE & $\begin{array}{l}\text { Transfer to } \\
\text { chronic care } \\
\text { hospital }\end{array}$ \\
\hline 8 & 76 & $\mathrm{~F}$ & $\begin{array}{l}\text { liver cirrhosis } \\
\text { (HCVI), hemiparesis }\end{array}$ & & weight loss & No & Yes & & Yes (Yes) & HRE & $\begin{array}{l}\text { Transfer to } \\
\text { chronic care } \\
\text { hospital }\end{array}$ \\
\hline 9 & 58 & $\mathrm{~F}$ & history of lithotripsy & & $\begin{array}{l}\text { fever, weight } \\
\text { loss }\end{array}$ & No & Yes & $\begin{array}{l}\text { kidney (CT and } \\
\text { MRI) }\end{array}$ & Yes (Yes) & HREZ & Resocialization \\
\hline 10 & 72 & M & collagen disease $\dagger$ & cough & & No & Yes & $\begin{array}{l}\text { liver }(\mathrm{CT}), \text { colon } \\
\text { (biopsy) }\end{array}$ & Yes (No) & HRS & Resocialization \\
\hline 11 & 52 & M & renal failure, diabetes & & weight loss & No & No & & Yes (No) & HREZ & Resocialization \\
\hline 12 & 43 & M & & & $\begin{array}{l}\text { fever, frequent } \\
\text { urination }\end{array}$ & No & No & $\begin{array}{l}\text { kidney (CT and } \\
\text { MRI) }\end{array}$ & Yes (No) & HRE & Resocialization \\
\hline 13 & 72 & $\mathrm{~F}$ & $\begin{array}{l}\text { malignant lympho- } \\
\text { ma, liver cirrhosis } \\
(\mathrm{HBVI})\end{array}$ & & $\begin{array}{l}\text { fever, weight } \\
\text { loss }\end{array}$ & No & No & & Yes (No) & HREZ & Resocialization \\
\hline 14 & 63 & M & $\begin{array}{l}\text { renal failure, diabe- } \\
\text { tes, history of } \\
\text { lithotripsy }\end{array}$ & & fever & No & Yes & Testicle (surgery) & Yes (Yes) & HREZ & $\begin{array}{l}\text { Transfer to } \\
\text { chronic care } \\
\text { hospital }\end{array}$ \\
\hline
\end{tabular}

$\dagger$ Case no. 10 did not receive corticosteroids or immunosuppressive agents regularly, as diagnosis of collagen disease with chronic polyarthritis was not definitive before hospitalization for tuberculosis.

E: ethambutol, H: isoniazid, HBVI: hepatitis B virus infection, HCVI: hepatitis C virus infection, MTB: miliary tuberculosis, t: not tested, R: rifampicin, S: streptomycin, Z: pyrazinamide

1, 4-9, and 14), whereas none required a lung biopsy. However, sputum, urine, and bone marrow were tested on the same day in only 5 patients (case 4, 5, 6, 8 and 14), and the mean time difference (days $\pm \mathrm{SD}$, range) between the date of the sputum + urine and bone marrow aspiration testing was 5 \pm 4 (range: 0-16 days).

Positive results were obtained from sputum and urine samples by smear, culture, and PCR in $3(21.4 \%), 13$ (92.9\%), and $12(85.7 \%)$ and $6(42.9 \%), 8(57.1 \%)$, and 11 (78.6\%) of the 14 patients with suspected MTB, respectively (Table 2). Three (100\%) of 3 patients (case 9, 10, and 12) with genitourinary (kidney 2, testicle 1) involvement showed positivity for $M$. tuberculosis bacilli and gene in urine sam- ples by both PCR and culture. Among the patients with suspected $(n=14)$ and clinical MTB $(n=9)$, the number of patients (\%) with positive results in sputum, urine, and both samples by either PCR or culture totaled $13(92.9 \%)$ and 9 (100\%), $12(85.7 \%)$ and $7(77.8 \%)$, and $11(78.6 \%)$ and 7 (77.8\%), respectively. Among 12 patients who required bone marrow aspiration, $6(75.0 \%)$ of 8 patients with positive results for bone marrow aspiration had positive results for both sputum and urine samples, whereas $3(75.0 \%)$ of 4 patients with negative results for bone marrow aspiration had positive results for both sputum and urine samples.

Table 3 a shows the detection of $M$. tuberculosis from sputum, urine, and both samples by PCR, smear, and culture in 
Table 2. Results for Sputum and Urine Samples by Smear, and Culture and PCR, and Bone Marrow Aspirations in Patients with Suspected and Clinical MTB.

\begin{tabular}{|c|c|c|c|c|c|c|c|c|c|c|c|}
\hline \multirow{2}{*}{ No. } & \multirow{2}{*}{$\begin{array}{l}\text { Age } \\
(\mathrm{yr})\end{array}$} & \multirow{2}{*}{ Gender } & \multirow{2}{*}{$\begin{array}{l}\text { Clinical } \\
\text { MTB }\end{array}$} & \multicolumn{3}{|c|}{ Sputum } & \multicolumn{3}{|c|}{ Urine } & \multirow{2}{*}{$\begin{array}{l}\text { Results in } \\
\text { both sputum } \\
\text { and urine } * *\end{array}$} & \multirow{2}{*}{$\begin{array}{l}\text { Results by bone } \\
\text { marrow } \\
\text { aspirations } * * *\end{array}$} \\
\hline & & & & smear & PCR & culture & smear & PCR & culture & & \\
\hline 1 & 43 & M & Yes & - & + & + & + & - & + & Positive & Positive \\
\hline 2 & 74 & $\mathrm{M}$ & No & + & + & + & - & + & + & Positive & Not tested \\
\hline 3 & 25 & $\mathrm{~F}$ & No & - & + & + & - & + & - & Positive & Not tested \\
\hline 4 & 83 & $\mathrm{~F}$ & Yes & - & + & + & - & - & - & Negative & Positive \\
\hline 5 & 76 & $\mathrm{~F}$ & Yes & - & - & + & - & + & + & Positive & Positive \\
\hline 6 & 73 & M & Yes & + & + & + & + & + & - & Positive & Positive \\
\hline 7 & 79 & M & Yes & - & + & + & - & - & - & Negative & Positive \\
\hline 8 & 76 & $\mathrm{~F}$ & Yes & $-\dagger$ & + & + & - & + & - & Positive & Positive \\
\hline 9 & 58 & $\mathrm{~F}$ & Yes & + & + & + & + & + & + & Positive & Positive \\
\hline 10 & 72 & M & Yes & $-\dagger$ & + & + & - & + & + & Positive & Negative \\
\hline 11 & 52 & $\mathrm{M}$ & No & $-\dagger$ & + & + & + & + & - & Positive & Negative \\
\hline 12 & 43 & M & No & - & - & - & + & + & + & Negative & Negative \\
\hline 13 & 72 & $\mathrm{~F}$ & No & - & + & + & - & + & + & Positive & Negative \\
\hline 14 & 63 & M & Yes & - & + & + & + & + & + & Positive & Positive \\
\hline \multicolumn{2}{|c|}{$\begin{array}{l}\text { Number of } \\
\text { results }(\%)\end{array}$} & positive & $\begin{array}{c}9 \\
(64.3 \%)\end{array}$ & $\begin{array}{c}3 \\
(21.4)\end{array}$ & $\begin{array}{c}12 \\
(85.7)\end{array}$ & $\begin{array}{c}13 \\
(92.9)\end{array}$ & $\begin{array}{c}6 \\
(42.9)\end{array}$ & $\begin{array}{c}11 \\
(78.6)\end{array}$ & $\begin{array}{c}8 \\
(57.1)\end{array}$ & $\begin{array}{c}11 \\
(78.6)\end{array}$ & $\begin{array}{c}8 / 12 \text { tested } \\
(66.7 \%)\end{array}$ \\
\hline
\end{tabular}

+ positive result, - negative result

$\dagger$ These were recognized as negative results by the investigators, although experienced screeners reported indeterminate results.

* Positive results from both sputum and urine samples were expressed as positive, whereas negative results from either sputum or urine samples were expressed as negative. However, in sputum and urine samples, positive results by either PCR or culture were judged as positive, whereas negative results by both PCR and culture were judged as negative.

** Positive results by either smear, culture, PCR or histologically findings were expressed as positive, whereas negative results by all of smear, culture, PCR and histologically findings were expressed as negative.

MTB: miliary tuberculosis, PCR: polymerase chain reaction

Table 3a. Detection of M. Tuberculosis from Sputum, Urine, and Both Samples between PCR, and Smear and Culture in Patients with Suspected MTB.

\begin{tabular}{ccccccr}
\hline PCR & \multicolumn{3}{c}{ Smear } & \multicolumn{3}{c}{ Culture } \\
\hline Both & Positive & Negative & Total & Positive & Negative & Total \\
\hline Positive & $8(28.6)$ & $15(53.6)$ & $23(82.1)$ & $19(67.9)$ & $4(14.3)$ & $23(82.1)$ \\
Negative & $1(3.6)$ & $4(14.3)$ & $5(17.9)$ & $2(7.1)$ & $3(10.7)$ & $5(17.9)$ \\
\hline Total & $9(32.1)$ & $19(67.9)$ & $28(100)$ & $21(75.0)$ & $7(25.0)$ & $28(100)$ \\
\hline Sputum & Positive & Negative & Total & Positive & Negative & Total \\
\hline Positive & $3(21.4)$ & $0(0)$ & $3(21.4)$ & $12(85.7)$ & $0(0)$ & $12(85.7)$ \\
Negative & $9(64.3)$ & $2(14.3)$ & $11(78.6)$ & $1(7.1)$ & $1(7.1)$ & $2(14.3)$ \\
\hline Total & $12(85.7)$ & $2(14.3)$ & $14(100)$ & $13(92.9)$ & $1(7.1)$ & $14(100)$ \\
\hline Urine & Positive & Negative & Total & Positive & Negative & Total \\
\hline Positive & $5(35.7)$ & $6(42.9)$ & $11(78.6)$ & $7(50.0)$ & $4(28.6)$ & $11(78.6)$ \\
Negative & $1(7.1)$ & $2(14.3)$ & $3(21.4)$ & $1(7.1)$ & $2(14.3)$ & $3(21.4)$ \\
\hline Total & $6(42.9)$ & $8(57.1)$ & $14(100)$ & $8(57.1)$ & $6(42.9)$ & $14(100)$ \\
\hline All)
\end{tabular}

All data were expressed as number of samples (\% of total).

patients with suspected MTB. Table $3 b$ shows the values of the sensitivity, specificity, PPV, and NPV between PCR, and smear and culture. No significant correlations were noted in the results for both or either sputum and urine samples between PCR, smear (all, $\mathrm{p}=1.0)$, and culture $(\mathrm{p}=0.0825$, 0.1429 and 0.5385 , respectively).

\section{Discussion}

We found a high detection rate $(85.7 \%)$ of M. tuberculosis gene and bacilli in urine using a combination of PCR and culture techniques in patients with suspected MTB. PCR can contribute to an early diagnosis with rapid detection and 
Table 3b. Sensitivity, Specificity, PPV, and NPV of PCR, when Compared with Smear and Culture.

\begin{tabular}{lcccccc}
\hline Correlation & \multicolumn{3}{c}{ Smear, value (95\% CI) } & \multicolumn{3}{c}{ Culture, value (95\% CI) } \\
\hline \multicolumn{1}{c}{ PCR } & Both & Sputum & Urine & Both & Sputum & Urine \\
\hline Sensitivity & $0.89(0.52-1.00)$ & $1.00(0.29-1.00)$ & $0.83(0.36-1.00)$ & $0.90(0.70-0.99)$ & $0.92(0.64-1.00)$ & $0.88(0.47-1.00)$ \\
Specificity & $0.21(0.06-0.46)$ & $0.18(0.02-0.52)$ & $0.25(0.03-0.65)$ & $0.43(0.10-0.82)$ & $1.00(0.03-1.00)$ & $0.33(0.04-0.78)$ \\
PPV & $0.35(0.16-0.57)$ & $0.25(0.05-0.57)$ & $0.46(0.17-0.77)$ & $0.83(0.61-0.95)$ & $1.00(0.74-1.00)$ & $0.64(0.31-0.89)$ \\
NPV & $0.80(0.28-0.99)$ & $1.00(0.16-1.00)$ & $0.67(0.09-0.99)$ & $0.60(0.15-0.95)$ & $0.50(0.01-0.99)$ & $0.67(0.09-0.99)$ \\
\hline
\end{tabular}

CI: confidence interval, NPV: negative predictive value, PPV: positive predictive value, PCR: polymerase chain reaction

identification of a specific $M$. tuberculosis gene, but the presence of live mycobacteria remains unknown. A culture may be able to investigate whether live or killed bacteria are present, but it does not allow for rapid detection. The combination of PCR with culture is therefore important for making an early and definitive diagnosis of active tuberculosis. The frequencies of patients with positive results for $M$. tuberculosis gene and bacilli in both sputum and urine using the combination techniques were $78.6 \%$ among patients with suspected MTB and $77.8 \%$ among those with clinical MTB. Twelve patients required bone marrow aspiration among 14 patients with suspected MTB, and $8(66.7 \%)$ of them had positive results (Table 2, 3a). In our study, three of four patients had negative results for bone marrow aspiration but positive results in both sputum and urine by PCR and/or culture, whereas two patients had positive results for bone marrow aspiration but negative results for both sputum and urine by PCR and/or culture (Table 2, 3a). The discrepancy in the results between PCR and/or culture, and bone marrow aspiration may be due to differences in the sampling time and differences in the specimens, such as detection of genes and/or bacilli, and pathological findings. We previously reported that $75 \%$ of the patients with suspected MTB showed histologically positive results by bone marrow aspiration (17). For a diagnosis of clinical MTB, the detection of M. tuberculosis genes and bacilli in both sputum and urine samples using the combination techniques may therefore be easier and safer than bone marrow aspiration.

The reason why $M$. tuberculosis is detectable in the urine of patients with pulmonary but not urogenital tuberculosis is still unclear. M. tuberculosis bacilli phagocytosed by macrophages may leave the systemic bloodstream via the lymph flow following vessel erosion and reach the medullary region of the kidney $(11-16,22)$. After the bacilli migrate to the cortico-medullary junction, the bacilli themselves and/or their gene may pass into the urine with and without the development of cortical caseating granulomas (11-16, 22). Urogenital tuberculosis is common in patients with extrapulmonary and disseminated tuberculosis and also occurs in 2$20 \%$ of patients with pulmonary tuberculosis $(23,24)$. Bentz et al. (25) reported that the rate of detection of $M$. tuberculosis bacilli by urine culture was $4.7 \%$ in patients with pulmonary tuberculosis that had not disseminated beyond the lungs. Our rates of detection of $M$. tuberculosis bacilli and gene in urine were quite high $(57.1 \%$ by culture and $78.6 \%$ by PCR). Although our results may have been partly attributable to patient selection and methodology, the urogenital involvement status was unknown in 11 of the 14 patients.

We found that PCR offered the best detection rate with sputum and urine samples, although not to a significant degree, followed by culture and smear techniques; the sensitivity for culture-confirmed sputum and urine samples was 0.92 and 0.86 , respectively, while the specificity was 1.00 and 0.33 , respectively. Therefore, PCR may offer a higher probability of faster and more accurate detection than other techniques for the diagnosis of patients with tuberculosis infections. Although none of the patients in our study had HIV, the M. tuberculosis gene detection rates from urine by PCR for pulmonary tuberculosis are known to be higher in patients with HIV (16-100\%) than in those without (6$38 \%$ ) (11). Torrea et al. (13) reported that, in 186 patients with pulmonary tuberculosis without HIV, the rate of genetic detection of $M$. tuberculosis from urine samples by PCR was $38 \%$. For patients without HIV, Kafwabulula et al. (14) compared the sensitivity and specificity of the Githui and Sechi methods of PCR detection for culture-confirmed urine samples and obtained figures of $55.6 \%$ and $98.4 \%$ for sensitivity and $28.6 \%$ and $98.4 \%$ for specificity, respectively. These results suggested that culture techniques might have higher accuracy than PCR using urine samples for diagnosis of patients with tuberculosis infections. Kolk et al. (16) reported that the detection ratio (number of positive results among the total number of samples tested) for M. tuberculosis genes using PCR with urine samples was $33.3 \%$, although the backgrounds of the patients were not mentioned. Rebollo et al. (12) demonstrated that, in 18 patients the detection ratios for $M$. tuberculosis bacilli and genes in urine samples in patients without disseminated pulmonary tuberculosis were $11.1 \%$ by culture and $0 \%$ by PCR, respectively. In contrast, the same rations in patients without disseminated pulmonary tuberculosis were $0 \%$ by culture and $0 \%$ by PCR, respectively.

Several limitations associated with the present study warrant mention. First, it had a retrospective design, and to avoid selection bias, the patients were carefully chosen by four independent investigators on the basis of archived chest HRCT pictures of all admitted patients with tuberculosis. However, the study was conducted in a single-blinded manner, as all the investigators knew that all of the patients had tuberculosis (Table 1). Second, the diagnosis of suspected 
MTB was made only on the basis of chest HRCT findings without reference to the histological findings of a biopsy or autopsy samples (i.e. definitive MTB). Therefore, the pathogenesis responsible for the detection of M. tuberculosis bacilli and gene in urine remained unknown. Third, we did not assess any blood samples for detection of tuberculosis infections, and we did not perform any blood culture for mycobacteria. Fourth, the sample size was rather small in comparison with previous studies (11-16).

In conclusion the present study using PCR and culture demonstrated high detection rates of $M$. tuberculosis in the urine of patients with pulmonary diffuse small nodular shadows on chest HRCT. A combination of PCR and culture compared favorably with bone marrow aspiration. We believe that detection of $M$. tuberculosis from urine and sputum samples may be easy and safe for patients with disseminated tuberculosis infections such as miliary tuberculosis.

\section{Author's disclosure of potential Conflicts of Interest (COI).}

Tomotaka Kawayama: Honoraria, Novartis Pharmaceuticals Japan, GSK Japan, Boehringer Ingelheim Japan, and AstraZeneca Japan. Takashi Kinoshita: Research funding, GSK Japan. Tomoaki Hoshino: Research funding, GSK Japan, Novartis Pharmaceuticals Japan and Chugai Pharmaceutical Co., Ltd.

\section{Acknowledgement}

The authors are grateful to Dr. Howard A. Young, National Cancer Institute-Frederick, for reading the manuscript and providing English language editing. The authors are also grateful to Prof. Tatsuyuki Kakuma, Biostatistics Center, Kurume University School of Medicine, for his support with the statistical analysis.

\section{Statement indicating the roles of the authors:}

Dr. T. Yokoyama contributed to the protocol design, analysis, and writing of the manuscript.

Dr. T. Kinoshita contributed to the protocol design, data collection, and analysis.

Dr. M. Okamoto contributed to the protocol design, data collection, and analysis.

Dr. K. Matsunaga contributed to the investigation of the radiographic findings as a thoracic radiologist.

Dr. T. Kamimura contributed to the investigation of the radiographic findings as a specialist in tuberculosis infections.

Dr. M. Kinoshita contributed to the pathological investigations as a pathologist.

Dr. T. Rikimaru contributed to the radiographic investigations as a thoracic radiologist.

Dr. K. Taguchi contributed to the radiographic investigations as a specialist in tuberculosis infections.

Prof. T. Hoshino supervised the protocol design and edited the manuscript.

Dr. T. Kawayama contributed to the protocol design and editing of the manuscript.

\section{References}

1. Uchimura K, Ngamvithayapong-Yanai J, Kawatsu L, et al. Perma- nent employment or public assistance may increase tuberculosis survival among working-age patients in Japan. Int J Tuberc Lung Dis 19: 312-318, 2015.

2. Maeda S, Hang NT, Lien LT, et al. Mycobacterium tuberculosis strains spreading in Hanoi, Vietnam: Beijing sublineages, genotypes, drug susceptibility patterns, and host factors. Tuberculosis (Edinb) 94: 649-656, 2014.

3. Masumoto S, Yamamoto T, Ohkado A, Yoshimatsu S, Querri AG, Kamiya Y. Factors associated with health-related quality of life among pulmonary tuberculosis patients in Manila, the Philippines. Qual Life Res 23: 1523-1533, 2014.

4. Ministry of Health, Labour and Welfare. Measures against Tuberculosis reports 2014 [Internet]. [cited 2016 Feb. 4] Available from: http://www.mhlw.go.jp/ (Japanese).

5. Murray CJ, Ortblad KF, Guinovart C, et al. Global, regional, and national incidence and mortality for HIV, tuberculosis, and malaria during 1990-2013: a systematic analysis for the Global Burden of Disease Study 2013. Lancet 384: 1005-1070, 2014.

6. Borekci S, Atahan E, Demir Yilmaz D, et al. Factors affecting the tuberculosis risk in patients receiving anti-tumor necrosis factor- $\alpha$ treatment. Respiration 90: 191-198, 2015.

7. Komatsu R, Sawada T. The role of international migration in infectious diseases: the HIV epidemic and its trends in Japan. Int $\mathbf{J}$ Health Serv 37: 745-759, 2007.

8. Kobashi Y, Mouri K, Yagi S, et al. Clinical features of immunocompromised and nonimmunocompromised patients with pulmonary tuberculosis. J Infect Chemother 13: 405-410, 2007.

9. Sharma SK, Mohan A, Sharma A, Mitra DK. Miliary tuberculosis: new insights into an old disease. Lancet Infect Dis 5: 415-430, 2005.

10. Mert A, Bilir M, Tabak F, et al. Miliary tuberculosis: clinical manifestations, diagnosis and outcome in 38 adults. Respirology $\mathbf{6}$ : 217-224, 2001

11. Green C, Huggett JF, Talbot E, Mwaba P, Reither K, Zumla AI. Rapid diagnosis of tuberculosis through the detection of mycobacterial DNA in urine by nucleic acid amplification methods. Lancet Infect Dis 9: 505-511, 2009.

12. Rebollo MJ, San Juan Garrido R, Folgueira D, et al. Blood and urine samples as useful sources for the direct detection of tuberculosis by polymerase chain reaction. Diagn Microbiol Infect Dis 56: 141-146, 2006.

13. Torrea G, Van de Perre P, Ouedraogo M, et al. PCR-based detection of the Mycobacterium tuberculosis complex in urine of HIVinfected and uninfected pulmonary and extrapulmonary tuberculosis patients in Burkina Faso. J Med Microbiol 54: 39-44, 2005.

14. Kafwabulula M, Ahmed $K$, Nagatake $T$, et al. Evaluation of PCRbased methods for the diagnosis of tuberculosis by identification of mycobacterial DNA in urine samples. Int J Tuberc Lung Dis 6: 732-737, 2002.

15. Sechi LA, Pinna MP, Sanna A, et al. Detection of Mycobacterium tuberculosis by PCR analysis of urine and other clinical samples from AIDS and non-HIV-infected patients. Mol Cell Probes 11: 281-285, 1997.

16. Kolk AH, Schuitema AR, Kuijper S, et al. Detection of Mycobacterium tuberculosis in clinical samples by using polymerase chain reaction and a nonradioactive detection system. J Clin Microbiol 30: 2567-2575, 1992.

17. Kinoshita M, Ichikawa $Y$, Koga H, Sumita S, Oizumi K. Reevaluation of bone marrow aspiration in the diagnosis of miliary tuberculosis. Chest 106: 690-692, 1994.

18. Tsukamura M. A review of the methods of identification and differentiation of mycobacteria. Infect Dis 3: 841-861, 1981.

19. Kusunoki S, Ezaki T, Tamesada M, et al. Application of colorimetric microdilution plate hybridization for rapid genetic identification of 22 Mycobacterium species. J Clin Microbiol 29: 1596-1603, 1991. 
20. Bergmann JS, Woods GL. Clinical evaluation of the Roche AMPLICOR PCR Mycobacterium tuberculosis test for detection of $M$. tuberculosis in respiratory specimens. J Clin Microbiol 34: 10831085, 1996.

21. D'Amato RF, Wallman AA, Hochstein LH, et al. Rapid diagnosis of pulmonary tuberculosis by using Roche AMPLICOR Mycobacterium tuberculosis PCR test. J Clin Microbiol 33: 1832-1834, 1995.

22. Daher Ede F, da Silva GB Jr, Barros EJ. Renal tuberculosis in the modern era. Am J Trop Med Hyg 88: 54-64, 2013.

23. Kulchavenya E. Extrapulmonary tuberculosis: are statistical reports accurate? Ther Adv Infect Dis 2: 61-70, 2014.
24. Figueiredo AA, Lucon AM. Urogenital tuberculosis: update and review of 8961 cases from the world literature. Rev Urol 10: 207217, 2008.

25. Bentz RR, Dimcheff DG, Nemiroff MJ, Tsang A, Weg JG. The incidence of urine cultures positive for Mycobacterium tuberculosis in a general tuberculosis patient population. Am Rev Respir Dis 111: 647-650, 1975.

The Internal Medicine is an Open Access article distributed under the Creative Commons Attribution-NonCommercial-NoDerivatives 4.0 International License. To view the details of this license, please visit (https://creativecommons.org/licenses/ by-nc-nd/4.0/).

(C) 2017 The Japanese Society of Internal Medicine http://www.naika.or.jp/imonline/index.html 